\title{
Numerical Thermal Performance of Closed Parabolic Trough Collector
}

\author{
Faissal Abdel-Hady ${ }^{\# 1}$, Azeez Bakare ${ }^{* 2}$, Mostafa Hamed ${ }^{* 3}$ \\ \# Chemical \& Material Dept., ${ }^{*}$ Mechanical Engineering Dept., Faculty of Engineering, \\ King Abdulaziz University, Jeddah Saudi Arabia \\ ${ }^{1}$ faisalhady@gmail.com \\ ${ }^{3}$ moshamed@yahoo.com \\ Faculty of Engineering, King Abdulaziz University, Jeddah Saudi Arabia \\ 2azeezbakare@yahoo.com
}

Abstract-in this study a thermal performance on a closed PTC's was carried out with the use of COMSOL ${ }^{\circledR}$ Multiphysics 4.3 software package. Two cases of parabolic trough designs were studied on a 3-dimensional model which was simulated taking into consideration the output of the HTF. The two cases studied were; a PTC having a glass cover in its aperture plane with no glass tube surrounding its absorber tube (closed case) and a PTC without a glass cover in its aperture plane and having no glass tube surrounding its absorber tube. The two cases have their trough thermally insulated. Also, various flow velocities were analyzed on six series connected PTC in order to estimate the best flow condition and to optimize its performance. Numerical simulation was used to present different temperature profile for the cases studied and the efficiency of the PTC was also estimated. Simulation showed that the collector with a glass cover in its aperture has a higher efficiency and better thermal performance than the one without glass cover in its aperture

Keyword- Heat transfer fluid, Parabolic trough collector, absorber tube, comsol® multiphysics, nonisothermal steady flow

\section{INTRODUCTION}

There have been substantial changes in the way people use various energy resources in the world for the past few decades. With an increasing endeavor by the government, academic bodies, industries to exploit alternative forms of energy and to enhance energy efficiency with maximization in cost and putting sustainability of energy into account. This motivates the exploitation and development of upcoming technologies to cut down the dependency on fossil fuels and the maximization of existing systems so as to reduce or minimize energy consumption. Due to the energy crises in 1973 and the high rise in crude oil prices [1] the clamour for other means of energy became more pronounced and focus was in the development of solar energy systems.

\begin{tabular}{|c|c|c|c|}
\hline \multicolumn{4}{|c|}{ Nomenclature } \\
\hline$f$ & Focal length of parabola & $\begin{array}{l}\text { Greek } \\
\text { symbols }\end{array}$ & \\
\hline$h$ & Height of parabola & $\mathrm{n}$ & Poisson's ratio \\
\hline$Y$ & $y$-axis of parabola & к & Conductivity \\
\hline$X$ & $\mathrm{x}$-axis of parabola & $\alpha$ & Coefficient of thermal expansion \\
\hline$s$ & Length of parabola arc & $\rho$ & Density \\
\hline$w_{a}$ & Width of parabola & $\varnothing$ & Incidence angle \\
\hline$l$ & $\begin{array}{l}\text { Length of the parabolic trough / receiver } \\
\text { tube }\end{array}$ & $v$ & Kinematic viscosity \\
\hline$D$ & Receiver tube outer diameter & $\mu$ & Viscosity \\
\hline$e$ & Reflector thickness & $\Omega$ & Thermal diffusivity \\
\hline$P_{r}$ & Prandtl number & $\varphi_{r}$ & Rim angle \\
\hline$C_{p}$ & Specific heat capacity at constant pressure & $\beta$ & Volume expansion coefficient \\
\hline$r_{r}$ & Rim radius of the collector & $\nabla$ & lagrangian \\
\hline $\mathbf{u}$ & Velocity field & $\boldsymbol{\theta}_{m}$ & Acceptance angle \\
\hline$t$ & Glass cover thickness & Acronyms & \\
\hline
\end{tabular}




\begin{tabular}{|llll|}
\hline$c$ & Geometric concentration ratio & PTC & Parabolic trough collector \\
$p$ & Pressure & CAD & Computer aided design \\
T & Absolute temperature & nitf & Non-isothermal flow \\
$\mathbf{n}$ & Normal vector of the boundary & $H T F$ & Heat transfer fluid \\
F & Volume force & $C F D$ & Computational fluid dynamics \\
Q & Heat source & FEA & Finite element analysis \\
E & Young's modulus & $3 D$ & Three dimensional \\
K & Stress tensor & $P V C$ & Polyvinyl chloride \\
& & $B C$ & Boundary condition \\
& & $P V$ & Photo voltaic \\
\hline
\end{tabular}

Solar concentrator is a device that accumulates sunlight from a wide area and directs it on a smaller receiver or exit [2]. Preferably, a solar concentrating system should have the following complimentary properties as design conditions: Energy efficient, construction/ maintenance cost-effectiveness and high durability. For the past couple of years, there have been various developments concerning the designs of the solar concentrators [2]. Some of the designs that have shown major impact to the solar technology are: Parabolic Concentrator, Fresnel Lens Concentrator, Quantum Dot Concentrator (QDC), Dielectric Totally Internally Reflecting Concentrator (DTIRC), Hyperboloid Concentrator, Compound Parabolic Concentrator (CPC), and Flat High Concentration Devices.

Parabolic Concentrators in two dimension is equivalent to a parabola, its main property that makes it different from other solar concentrators is that all parallel rays gotten from the sun is being focused to a single focal point but it has a limitation of requiring a tracking system in order to achieve optimum performance and efficiency. Construction of the parabolic concentrator mostly use the truncated part of the parabola rather than using the whole part of the parabola curve.

The very first applicable work on parabolic trough collectors can be traced back to 1870 as stated by Fernandez-Garcia et al [3] where John Ericsson designed and constructed a collector with an aperture area of $3.25 \mathrm{~m}^{2}$ and it was used to drive an engine of $373 \mathrm{~W}$ successfully. In 1928, Pasteur carried out solar Distillation with the use of solar concentrators by focusing the solar radiation to a boiler made of copper [4]. In 1975, three troughs with different material but the same principle were constructed and tested at Sandia as described by Fernandez-Garcia et al [3], it can also be compared with the work of Valan Arasu and Sornakumar [5] where the $7 \mathrm{~mm}$ total thickness reinforced fiberglass parabolic trough was subjected to a load test that is equivalent to $34 \mathrm{~m} / \mathrm{s}$ blowing wind. Luz International Limited, a company collaborated by America and Israel, constructed three different generations of PTCs in 1979. From 1984 to 1990 they also built Nine (9) Solar Electric generating system (SEGS) [6] which uses PTC's to heat thermal fluid also known as heat transfer fluid (HTF) to produce steam to drive a steam Rankine cycle Power Plant. Also in 1992 a study of optical, structural and thermal subsystems of PTCs and their performance were carried out by Thomas and Guven [1].

In the beginning of 21 st century there were demand for more performance and cost effectiveness of the parabolic trough in order to gain more competitiveness with the other forms of energy generation (e.g. fossilfuel, Natural gas and coal technology etc.) and this resulted to more researches on cost analysis on the old and the newly designed parabolic troughs with the sole purpose of its widely acceptance while improving on the design, construction and performance of the trough. In 2002, two models of parabolic trough collectors: Euro Trough ET100 and ET150 were developed for process heat applications (Using Solar steam) and generation of solar Power .Having 82:1 optical concentration ratio with operating temperature of over $500^{\circ} \mathrm{C}$ they have the ability of using different types of heat transfer fluid ranging from synthetic oil, molten salt to water/steam. Achievement of $14 \%$ of cost reduction were realized in the design [7]. Two sets of PTC's named SGX1 and SGX2 were designed and constructed by Solargenix Energy in 2003 [8] with the aim of improving cost and efficiency of the collectors. They have improved subsystems like the incorporation of solar tracking devices/controls and support drive units. They achieved a $10 \%$ increased performance and $20 \%$ cost reduction when compared with earlier designed trough. 


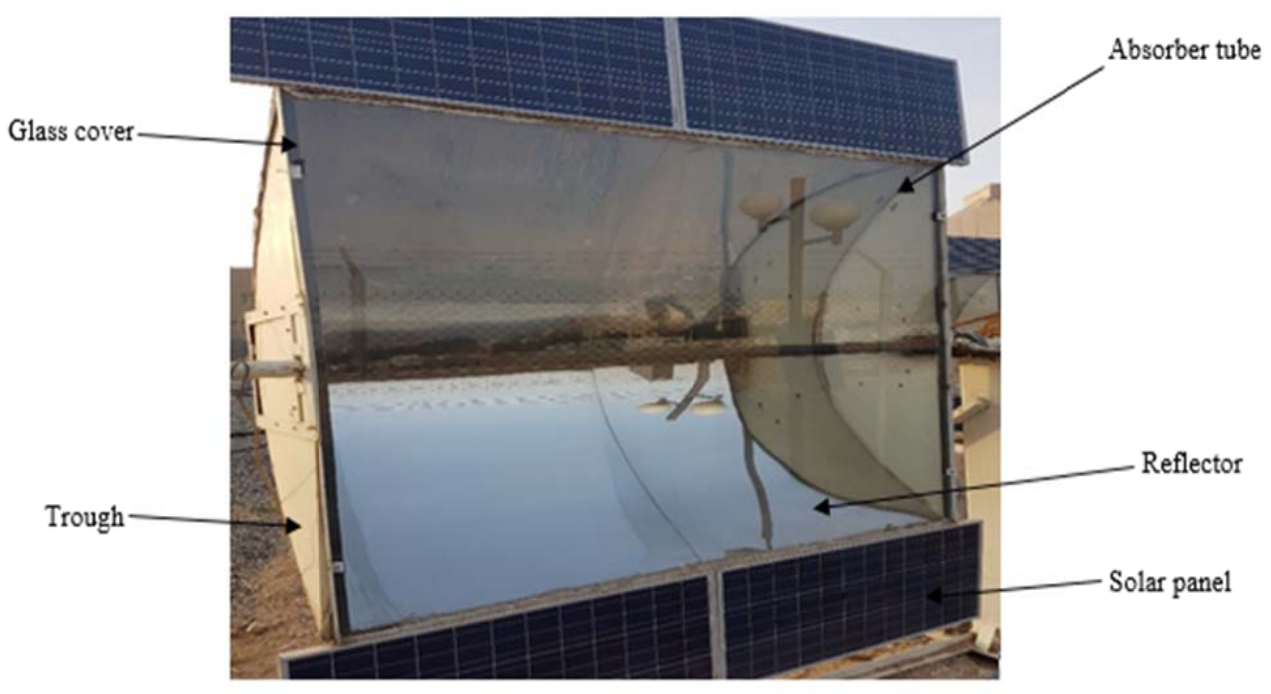

Fig. 1. A parabolic trough collector

In the late 2003, Sargent \& Lundy LLC Consulting Group in collaboration with the National Research Council (NRC) Committee [9] carried out a technology cost and performance assessment on PTC's and Power tower solar technology while including their performance forecasts. They came up with a conclusion that substantial reduction of cost can be attained if sensible deployment of concentrating solar power technologies occurs. Kalogirou [10] in 2004 carried out a general survey of different types of solar thermal collectors and their various applications.

There were various work carried out on the analysis of PTC's from the year 2005 to 2010, ranging from the thermal performance of the parabolic receivers at various operating solar power plant [6] to the analytic modelling of solar power plant whose function is mainly dependent on parabolic linear collectors while also emphasizing on how to improve the design/ performance with overall cost reduction [11]. In 2013, Chemisana, et.al [12] carried out an optical assessment on the performance of solar reflective concentrators, they were able to design and test the optical quality of a solar collector using absorber reflection method. In 2015, Aranzazu et.al [15] worked on the design of an industrial PTC (small-sized) taking into consideration three cases, which focused on the aperture (with and without glass cover), the absorber tube (with and without glass tube cover) and the reflector back (with and without thermal insulation). Their numerical analysis was on a 2-dimensional model but even though they considered the absorber temperature they didn't take into account the HTF during computational fluid dynamic analysis which is a critical factor in determining the performance of the design. So, they concluded that the collector design with a glass cover only in the aperture plane with thermal reflector back has the highest heat loss and the lowest efficiency as compared to a similar design that doesn't have a thermal reflector back. This shows a discrepancy in the normal heat transfer analysis.

In this study a thermal performance on PTC's was carried out with the use of COMSOL Multiphysics 4.3 software package. Two cases of parabolic trough design were studied. Unlike the work of [15], a 3-dimensional model was simulated taking into consideration the output of the HTF during computational fluid dynamic analysis. Also, various flow velocities were analyzed on six series connected PTC in order to estimate the best flow condition and to optimize its performance and efficiency. Numerical simulation was used to present different temperature profile for the cases studied and the efficiency of the PTC was also estimated.

\section{DESIGN}

\section{A. Geometry}

The design of the geometrical model was done with the use of Dassault Systèmes SolidWorks ${ }^{\circledR}[13]$ software. The geometry is as shown in Fig. 2 below. The geometrical parameters are highlighted in table 1. It is adapted from Faissal et al [14]. The design is such that the trough aperture is desired to accommodate a glass cover in order to reduce convection heat loss, increase the structural rigidity of the trough and improve cleaning maintenance. Therefore, an adequate clearance was provided between focal point and aperture plane. The focal point is also expected to be inside the parabolic shape thus, the focal length is given to be less than the height of the parabola. Also the geometric ratio is gotten by calculating the ratio of aperture area to outer absorber surface area [14], [15]. The rim angle is calculated by using both aperture width and the focal length [16]. The distance between height and focal length of the parabola is the subtraction of the focal length from parabolic height. 
TABLE I. The geometrical properties of the parabolic trough collector [14]

\begin{tabular}{ccc}
\hline \hline Parameters & Symbols & Dimension (mm) \\
\hline Height of the parabola & $\mathrm{h}$ & 490 \\
Focal length & $\mathrm{f}$ & 404 \\
Trough length & 1 & 1720 \\
width & $w_{a}$ & 1693.5 \\
Length of parabolic arc & $\mathrm{s}$ & 1965.5 \\
Absorber tube outer & $\mathrm{D}$ & 42 \\
diameter & $\mathrm{t}$ & 4 \\
Glass cover thickness & $\mathrm{e}$ & 0.5 \\
Reflector thickness & $\mathrm{c}$ & $40.3: 1$ \\
Geometric concentration & & $92.63^{\circ}$ \\
ratio & $\varphi_{r}$ & 847.7 \\
Rim angle & $r_{r}$ & $1.83^{\circ}$ \\
Rim radius & $\theta_{m}$ & \\
Acceptance angle & &
\end{tabular}

The trough was also designed to have wings which accommodated PV panels. The energy generated from the PV panels was used to power the solar tracking mechanism and some other electrical component that makes up the whole system.

\section{B. Materials}

The materials that makes up the PTC model were chosen in accordance to the desired properties and characteristics in order to achieve maximum heat transfer performance while taking into consideration the cost and readily availability of the materials. The parabolic trough is made of PVC materials (glass fibre with polyester matrix) of $2.3 \mathrm{~mm}$ thickness which is characteristically lightweight, thermally insulated and rigid and it accommodates a reflector material of a $0.5 \mathrm{~mm}$ thick stainless steel sheet fused to a $3 \mathrm{M}^{\mathrm{TM}}$ [19] polymeric mirror [14]. The absorber tube is made up of copper coated with rust -oleum ${ }^{\mathrm{TM}}$ which aids in the absorptivity of the tube. Also, another material that makes up the PTC model is a clear anti-reflective glass (Quartz) which protects the trough reflector surface from abrasions due to sand, dust, hail etc. while aiding in the rigidity of the whole structure. Finally, motor oil SAE 10w30 was used as the HTF. The thermo-physical properties of the HTF at varying temperature is given in Table 2 below while the physical, thermal and optical properties of the remaining selected materials is given in Table 3. The cavity that exist within the trough is occupied with air.

TABLE II. The thermo-physical properties of the HTF at varying temperature [16], [17].

\begin{tabular}{|c|c|c|c|c|c|c|c|c|}
\hline $\begin{array}{l}\text { Temperatur } \\
\text { e }\left({ }^{\circ} \mathbf{K}\right)\end{array}$ & $\begin{array}{c}\text { Density } \\
\rho \\
\left(\mathrm{kg} / \mathrm{m}^{3}\right)\end{array}$ & $\begin{array}{c}\text { Specific } \\
\text { heat } C_{p} \\
\left(\mathbf{k J} / \mathbf{k g}^{\circ}\right. \\
\mathbf{K})\end{array}$ & $\begin{array}{c}\text { Viscosit } \\
\mathbf{y} \mu \\
\left(\mathrm{N} / \mathbf{s m}^{2}\right)\end{array}$ & $\begin{array}{c}\text { Kinemat } \\
\text { ic } \\
\text { viscosity } \\
v\left(10^{-4}\right. \\
\left.\mathbf{m}^{2} / \mathbf{s}\right)\end{array}$ & $\begin{array}{c}\text { Thermal } \\
\text { conductivi } \\
\text { ty } \kappa \\
\left(\mathbf{W} / \mathbf{m}^{\circ} \mathbf{K}\right)\end{array}$ & $\begin{array}{c}\text { Thermal } \\
\text { diffusivity } \\
\Omega\left(10^{-}\right. \\
\left.{ }^{8} \mathbf{m}^{\mathbf{2}} / \mathbf{s}\right)\end{array}$ & $\begin{array}{l}\text { Prandtl } \\
\text { numbe } \\
\text { r Pr }\end{array}$ & $\begin{array}{c}\text { Volume } \\
\text { expansion } \\
\text { coefficient } \beta \\
\left(10^{-4} /{ }^{\circ} \mathrm{K}\right)\end{array}$ \\
\hline 260 & 908 & 1.76 & 12.23 & 135 & 0.149 & 9.32 & 144500 & 7 \\
\hline 280 & 896 & 1.83 & 2.17 & 24.2 & 0.146 & 8.9 & 27200 & 7 \\
\hline 300 & 884 & 1.91 & 0.486 & 5.5 & 0.144 & 8.53 & 6450 & 7 \\
\hline 320 & 872 & 1.99 & 0.141 & 1.62 & 0.141 & 8.13 & 1990 & 7 \\
\hline 340 & 860 & 2.08 & 0.053 & 0.62 & 0.139 & 7.77 & 795 & 7 \\
\hline 360 & 848 & 2.16 & 0.025 & 0.3 & 0.137 & 7.48 & 395 & 7 \\
\hline 380 & 836 & 2.25 & 0.014 & 0.17 & 0.136 & 7.23 & 230 & 7 \\
\hline 400 & 824 & 2.34 & 0.009 & 0.11 & 0.134 & 6.95 & 155 & 7 \\
\hline
\end{tabular}



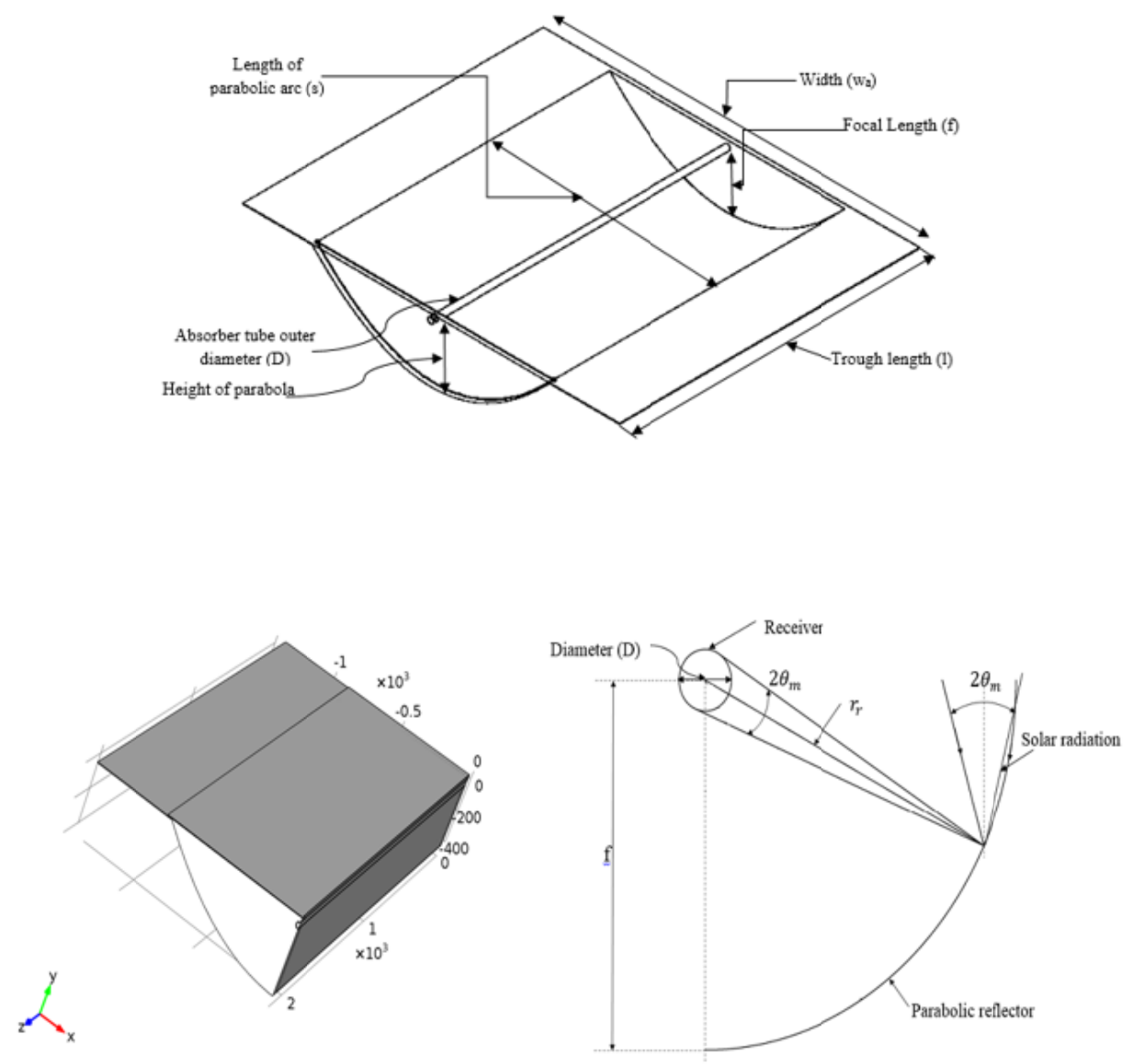

Fig. 2. 2D and 3D geometry of the PTC Design.

TABLE III. The physical, thermal and optical properties of the remaining selected materials

\begin{tabular}{|c|c|c|c|c|}
\hline Parameter & Units & Absorber Tube & PVC & Glass Cover \\
\hline Density $(\rho)$ & $\mathrm{kg} / \mathrm{m} 3$ & 8700 & 1760 & 2200 \\
\hline $\begin{array}{c}\text { Thermal } \\
\text { conductivity } \\
(\kappa)\end{array}$ & $\mathrm{W} / \mathrm{m}^{\circ} \mathrm{K}$ & 400 & 0.1 & 1.1 \\
\hline $\begin{array}{l}\text { Heat capacity } \\
\qquad\left(C_{p}\right)\end{array}$ & $\mathrm{J} / \mathrm{kg}^{\circ} \mathrm{K}$ & 385 & 4000 & 480 \\
\hline $\begin{array}{l}\text { Coefficient of } \\
\text { thermal } \\
\text { expansion }(\alpha)\end{array}$ & ${ }^{\circ} \mathrm{K}^{-1}$ & $16.6 \times 10^{-6}$ & $100 \times 10^{-6}$ & $9 \times 10^{-6}$ \\
\hline $\begin{array}{l}\text { Poisson ratio } \\
\text { (n) }\end{array}$ & - & 0.33 & 0.28 & 0.3 \\
\hline $\begin{array}{c}\text { Relative } \\
\text { permeability }\end{array}$ & - & 1 & - & 1 \\
\hline $\begin{array}{l}\text { Refractive } \\
\text { index }\end{array}$ & - & - & - & 1.5 \\
\hline $\begin{array}{c}\text { Young } \\
\text { Modulus (E) }\end{array}$ & $\mathrm{Pa}$ & $117 \times 10^{9}$ & $2.9 \times 10^{9}$ & $74 \times 10^{9}$ \\
\hline $\begin{array}{c}\text { Relative } \\
\text { permittivity }\end{array}$ & - & 1 & 2.9 & 4.2 \\
\hline
\end{tabular}




\section{III.MODELLING}

A three dimensional symmetrical half model of the PTC cross section was chosen for the numerical simulation for the two cases under study because complete collector efficiency is to be calculated for which may not be achieved accurately if a two dimensional model was chosen. A symmetrical half model was analyzed in order to reduce computational cost and time while maintaining the computational accuracy.

The two cases that were studied are:

- Case 1: A PTC having a glass cover in its aperture plane with no glass tube surrounding its absorber tube

- Case 2: A PTC without a glass cover in its aperture plane and having no glass tube surrounding its absorber tube

Since the trough which accommodates the reflector was made with PVC which has a characteristically low thermal conductivity, thereby it can be assumed that the back of the reflector is properly thermally insulated. The numerical analysis was done for six PTC's connected in series.

\section{A. Computational analysis}

A non-isothermal steady flow (nitf) steady state analysis was carried out for the numerical simulation. The individual parameters that were taken into consideration contributed to the modelling of the heat transfer in the collector walls. The computational domain and boundary conditions that were taken into consideration are as follows:

1) Domain: The computational domain is made up of air situated inside the parabolic trough, heat transfer fluid, parabolic trough (PVC) which houses the reflector, absorber tube and flat glass cover in the aperture plane. Case 1 is made up of five (5) domain while case 2 has four (4) domain because of non-inclusion of flat glass cover.

2) Boundary conditions: A no-slip boundary condition was chosen for fluid/solid wall interface while the other parameters where the boundary conditions were applied are also listed below

3) Fluids: The two categories of fluid taken into consideration are air and HTF. The governing equation are as follows:

$$
\begin{gathered}
\rho(\mathbf{u} . \nabla) \mathbf{u}=\nabla \cdot\left[-p \mathbf{I}+\mu\left(\nabla \mathbf{u}+(\nabla \mathbf{u})^{T}\right)-\frac{2}{3} \mu(\nabla \cdot \mathbf{u}) \mathbf{I}\right]+F \\
\nabla \cdot(\rho \mathbf{u})=0
\end{gathered}
$$

Where $\rho$ is the density of the fluids, $\mathbf{u}$ is the velocity field, $\nabla$ represents the Laplacian operator, $p$ is the Pressure of the fluids, $\mu$ is the fluid viscosity, $F$ is the volume force.

4) Thermal insulation: Thermal insulation boundary condition was applied to the cross sectional ends of the receiver tube according to the equation below

$$
\text { -n. }(-k \nabla T)=0
$$

Where $\mathbf{n}$ represents the normal vector of the boundary, $k$ is the thermal conductivity and $T$ is the absolute temperature

5) Walls: The interface wall between fluid and solid domain (i.e. the contact surface between the fluids (HTF and air) and the solid walls (PTC, copper and glass) was imposed with no-slip boundary condition according to the equation below

$$
\mathbf{u}=0
$$

6) Initial values: The initial values were applied on the whole geometry during numerical analysis taking velocity $(\mathbf{u})$, pressure $(p)$ and temperature $(T)$ as:

$$
T=293.15\left[{ }^{\circ} \mathrm{K}\right], \mathbf{u}=0 \frac{\mathrm{m}}{\mathrm{s}} \text { and } p=0 \mathrm{pa}
$$

7) Heat transfer in solids: The boundary chosen for heat transfer in solids are PVC, glass cover and the copper tube since the sun's irradiation falls on the entire geometry. The governing equation can be given as

$$
\rho c_{p} \mathbf{u} \cdot \nabla T=\nabla \cdot(k \nabla T)+Q
$$

Where, $Q$ is the heat source and $c_{p}$ is the specific heat capacity at constant pressure.

8) Inlets: The boundary condition chosen for the inlet during the non-isothermal flow condition is the normal inflow velocity. The inflow velocities considered for the performance analysis were $0.01 \mathrm{~m} / \mathrm{s}$, $0.0226 \mathrm{~m} / \mathrm{s}, 0.0452 \mathrm{~m} / \mathrm{s}, 0.11 \mathrm{~m} / \mathrm{s}, 0.135 \mathrm{~m} / \mathrm{s}, 0.158 \mathrm{~m} / \mathrm{s}$ and $0.181 \mathrm{~m} / \mathrm{s}$. With the use of laminar flow 
condition the various velocities were chosen in order to simulate the effect of minimal changes in velocity within a range of $0.01 \mathrm{~m} / \mathrm{s}$ to $0.181 \mathrm{~m} / \mathrm{s}$. the bounding equation is given as

$$
\mathbf{u}=-U_{o} \mathbf{n}
$$

Where $U_{o}=$ the normal inflow velocity and $\mathbf{n}=$ normal vector of the boundary

Laminar flow condition was chosen in order to determine the optimum heat absorption capability of the HTF and also to be able to efficiently determine the performance of the model.

9) Outlet: The boundary condition for the outlet flow is the pressure no viscous stress condition and it is applied on the outlet of the absorber tube according to the equation below

$$
p=p_{o}, \quad\left[\mu(\nabla \mathbf{u})+(\nabla \mathbf{u})^{T}-\frac{2}{3} \mu(\nabla \cdot \mathbf{u}) \mathbf{I}\right] \cdot \mathbf{n}=0
$$

$$
\text { Where } p_{o}=0 \mathrm{~Pa}
$$

10) Symmetry: Since the simulation was done on a half model of the PTC cross section, there is a need to introduce a symmetry boundary condition so that the result will account for the full model. The boundary condition for symmetry boundaries prescribes no penetration and vanishing shear stresses. The boundary condition is dependent on Dirichelet condition [18] as given in the equation below as

$$
\begin{gathered}
\mathbf{u} . \mathbf{n}=0, \quad \mathbf{K}-(\mathbf{K} \cdot \mathbf{n}) \mathbf{n}=0 \\
\mathbf{K}=\left[\mu\left(\nabla \mathbf{u}+(\nabla \mathbf{u})^{T}\right] \mathbf{n}\right. \\
-\mathbf{n} \cdot(-k \cdot \nabla T)=0
\end{gathered}
$$

11) Convective cooling: Convective cooling was applied on the external part of the geometry due to direct contact of atmospheric condition over it. The heat transfer coefficient (h) was taken as $5 \mathrm{w} / \mathrm{m}^{2} \mathrm{k}$, while the external temperature $T_{\text {ext }}$ was assumed to be $300^{\circ} \mathrm{K}$ because the average external temperature of Jeddah, Makkah province Saudi Arabia is around $300^{\circ} \mathrm{K}$. The governing equation is given as

$$
-\mathbf{n} .(-k \cdot \nabla T)=h \cdot\left(T_{\text {ext }}-T\right)
$$

12) Volume force: Volume force is associated to the HTF and it is along the flow of the fluid. The governing equation is given as

$$
\begin{gathered}
\rho(\mathbf{u} . \nabla) \mathbf{u}=\nabla \cdot\left[-p i+\mu\left(\nabla \mathbf{u}+(\nabla \mathbf{u})^{T}\right)-\frac{2}{3} \mu(\nabla . \mathbf{u}) \mathbf{I}\right]+F \\
\text { Where } F=-\rho g\left(\mathrm{~N} / \mathrm{m}^{3}\right)
\end{gathered}
$$

13) Temperature: The temperature contributes to the inlet condition of the collector. Since six numbers of PTC's in series were considered, therefore the output temperature of a particular collector is the input temperature of the next collector and this process is repeated up to the last collector input.

14) Heat source: The heat source is applied to the copper tube walls since the irradiation is being transmitted from the reflective surface to the absorber tube. The governing equation can be given as

$$
\begin{gathered}
\rho C_{p} \mathbf{u} . \nabla T=\nabla \cdot(k \nabla T)+Q \\
Q=\frac{P_{t o t}}{V}
\end{gathered}
$$

Where the total power $\left(P_{t o t}\right)$ which is obtained to be $1755.6 \mathrm{~W}$ can be calculated from;

$$
P_{\text {tot }}=E_{b} A_{c} \cos (\varnothing)
$$

Where $E_{b}$ is the average irradiation of Jeddah given as $940 \mathrm{~W} / \mathrm{m}^{2}$ from an experimental data obtained in King Abdulaziz University on the 23rd November 2016 as shown in Fig 3. 


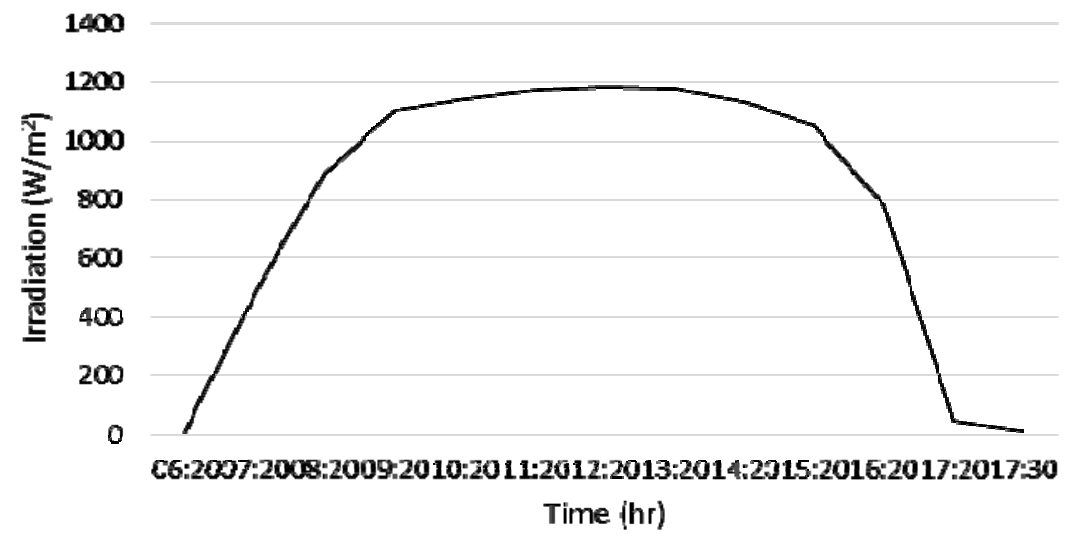

Fig 3. Irradiation of Jeddah for $23^{\text {rd }}$ Nov. 2016

Also, the average incidence angle $(\varnothing)$ was gotten to be $23.67^{\circ}$ while the aperture area $\left(A_{c}\right)$ of the collector was calculated to be $2.913 \mathrm{~m} 2$ (from Table 1 ) and $V$ is the volume of the absorber tube.

Note: $P_{t o t}$ was multiplied by 0.7 due to the implication of end effect of the PTC.

B. Numerical mesh

The numerical mesh size of the model is a function of the criticality of the domain/ boundary layer under consideration. The sizes are of two categories which are the normal and fine sizes. The mesh was calibrated for fluid dynamics. The normal size was chosen for the fluid domain while the fine size was chosen for the solid domain/ boundary layers. The characteristics of the two mesh sizes can be seen in Table 4 below, while Table 5 show the overall mesh statistics. Fig 4 show the numerical mesh distribution of the model.

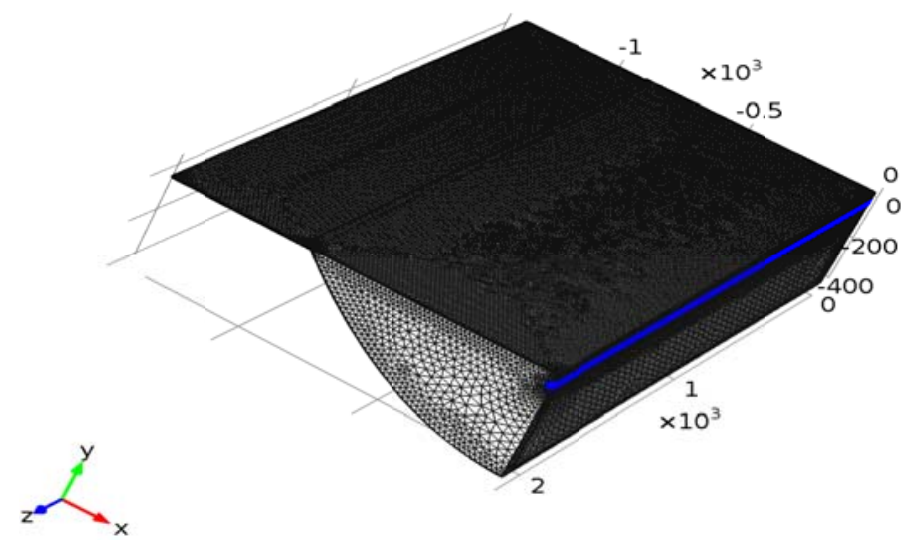

Fig. 4 Numerical mesh distribution of half modeled PTC

TABLE IV. Numerical mesh characteristics

\begin{tabular}{ccc}
\hline \hline Description & $\begin{array}{c}\text { Size 1 } \\
\text { Value }(\mathbf{m m})\end{array}$ & $\begin{array}{c}\text { Size 2 } \\
\text { Value (mm) }\end{array}$ \\
\hline Maximum element size & 52.3 & 41.4 \\
Minimum element size & 15.6 & 7.81 \\
Resolution of curvature & 0.6 & 0.5 \\
Resolution of narrow & 0.7 & 0.8 \\
$\begin{array}{c}\text { regions } \\
\text { Maximum element growth } \\
\text { rate }\end{array}$ & 1.15 & 1.13 \\
Predefined size & Normal & Fine \\
\hline \hline
\end{tabular}


TABLE V. Numerical mesh statistics

\begin{tabular}{cc}
\hline \hline Mesh Properties & Value \\
\hline Minimum element quality & $7.196 \times 10^{4}$ \\
Average element quality & 0.5412 \\
Tetrahedral elements & 337655 \\
Prism elements & 32924 \\
Triangular elements & 90299 \\
Quadrilateral elements & 2308 \\
Edge elements & 2920 \\
Vertex elements & 34 \\
\hline \hline
\end{tabular}

\section{IV.RESULTS AND DISCUSSION}

The results obtained from the numerical simulation are of three categories. Two out of the three categories depicted the performance of the PTC while the last one was on the efficiency of the PTC. The first category is centered on the output temperatures of the six series connected PTC's while the second category showed the average temperature of the computational domain studied.

The results of the two cases studied under the first category can be seen in Table 6 and 7 below. It show the output temperature of the two configuration when subjected to the same parameters at varying HTF flow velocity.

TABLE VI. Case 1: Output temperature of simulated half-PTC with glass cover at varying velocity

\begin{tabular}{|c|c|c|c|c|c|c|c|}
\hline $\mathbf{S} / \mathbf{N}$ & $\begin{array}{c}\text { Velocity } \\
(\mathrm{m} / \mathrm{s})\end{array}$ & $\begin{array}{c}\text { Collector } 1 \\
\left({ }^{\circ} \mathbf{K}\right)\end{array}$ & $\begin{array}{c}\text { Collector } \\
2 \\
\left({ }^{\circ} \mathbf{K}\right) \\
\end{array}$ & $\begin{array}{c}\text { Collector } \\
\mathbf{3} \\
\left({ }^{\circ} \mathbf{K}\right) \\
\end{array}$ & $\begin{array}{c}\text { Collector } 4 \\
\left({ }^{\circ} \mathbf{K}\right)\end{array}$ & $\begin{array}{c}\text { Collector } 5 \\
\left({ }^{\circ} \mathbf{K}\right)\end{array}$ & $\begin{array}{c}\text { Collector } 6 \\
\left({ }^{\circ} \mathbf{K}\right)\end{array}$ \\
\hline 1 & 0.0100 & 479.16 & Nil & Nil & Nil & Nil & Nil \\
\hline 2 & 0.0226 & 387.27 & 484.11 & 580.81 & Nil & Nil & Nil \\
\hline 3 & 0.0452 & 352.58 & 403.80 & 459.09 & 516.70 & 573.83 & Nil \\
\hline 4 & 0.1100 & 330.24 & 362.33 & 391.59 & 419.02 & 447.03 & 474.96 \\
\hline 5 & 0.1350 & 323.92 & 352.05 & 378.31 & 402.74 & 425.97 & 449.10 \\
\hline 6 & 0.1580 & 319.49 & 344.31 & 367.97 & 390.17 & 411.21 & 431.39 \\
\hline 7 & 0.1810 & 315.81 & 337.96 & 359.21 & 379.36 & 398.52 & 416.86 \\
\hline
\end{tabular}

Note: Inlet temperature of collector 1 is $293.15^{\circ} \mathrm{K}$, while every output temperature is an input temperature of the successive collector. The Nil values show non-convergence of the simulation i.e. divergence of the linear iterations.

TABLE VII. Case 2: Output temperature of simulated half-PTC without glass cover at varying velocity

\begin{tabular}{|c|c|c|c|c|c|c|c|}
\hline $\mathbf{S} / \mathbf{N}$ & $\begin{array}{c}\text { Velocity } \\
(\mathrm{m} / \mathrm{s})\end{array}$ & $\begin{array}{c}\text { Collector } 1 \\
\left({ }^{\circ} \mathbf{K}\right)\end{array}$ & $\begin{array}{c}\text { Collector } \\
2 \\
\left({ }^{\circ} \mathbf{K}\right)\end{array}$ & $\begin{array}{c}\text { Collector } \\
\mathbf{3} \\
\left({ }^{\circ} \mathbf{K}\right)\end{array}$ & $\begin{array}{c}\text { Collector } 4 \\
\left({ }^{\circ} \mathbf{K}\right)\end{array}$ & $\begin{array}{c}\text { Collector } 5 \\
\left({ }^{\circ} \mathbf{K}\right)\end{array}$ & $\begin{array}{c}\text { Collector } 6 \\
\left({ }^{\circ} \mathrm{K}\right)\end{array}$ \\
\hline 1 & 0.0100 & 470.47 & Nil & Nil & Nil & Nil & Nil \\
\hline 2 & 0.0226 & 385.23 & 475.14 & 566.11 & Nil & Nil & Nil \\
\hline 3 & 0.0452 & 352.04 & 402.02 & 454.54 & 507.99 & 560.17 & Nil \\
\hline 4 & 0.1100 & 329.51 & 360.69 & 389.17 & 425.78 & 442.15 & 468.16 \\
\hline 5 & 0.1350 & 323.29 & 350.59 & 376.11 & 399.85 & 422.25 & 444.17 \\
\hline 6 & 0.1580 & 318.90 & 343.03 & 365.94 & 387.42 & 407.78 & 427.22 \\
\hline 7 & 0.1810 & 315.09 & 336.58 & 357.09 & 376.53 & 394.99 & 412.65 \\
\hline
\end{tabular}

Note: Inlet temperature of collector 1 is $293.15^{\circ} \mathrm{K}$, while every output temperature is an input temperature of the successive collector. The Nil values show non-convergence of the simulation i.e. divergence of the linear iterations. 
By comparing the two Tables (i.e. Tables 6 and 7) above and Fig. 5 , it can be deducted that the output temperature for every collector in case 1 is higher than that of case 2 at all velocities, which show that case 1 has a higher performance than case 2. It can also be noted that with increase in flow velocity, the change in temperature between the two cases for a particular collector decreases. Therefore, as the flow velocity increases the significance of glass cover to the effect of output temperature reduces due to the impact of free convection on the absorber tube.

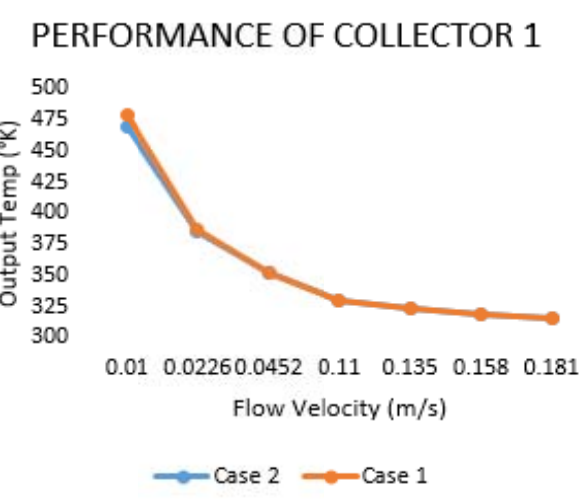

PERFORMANCE OF COLLECTOR 3

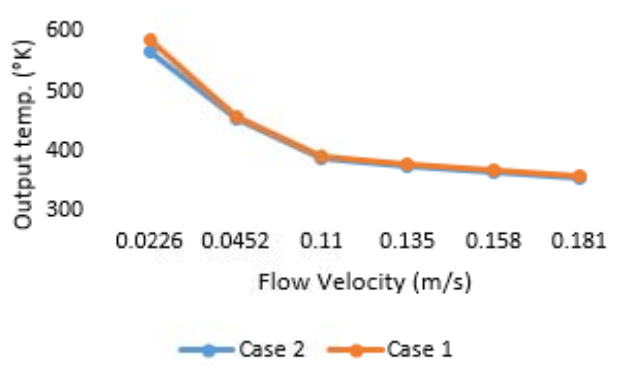

\section{PERFORMANCE OF COLLECTOR 2}

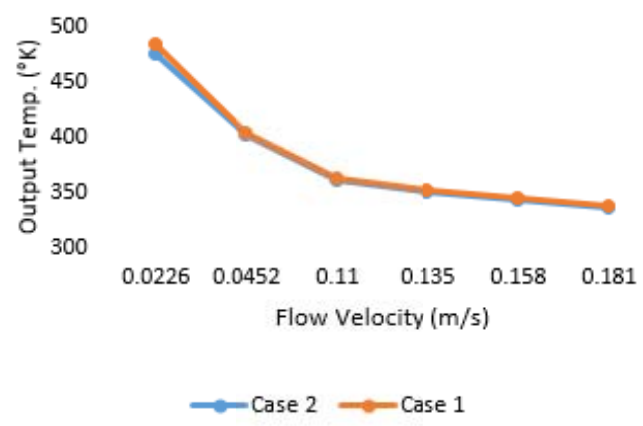

PERFORMANCE OF COLLECTOR 4

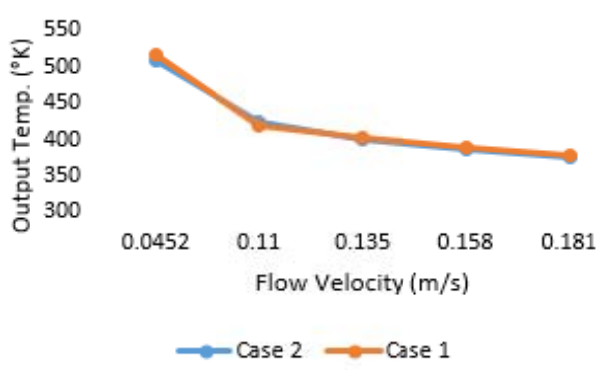

Fig. 5. Performance of PTC for collectors 1-4.

Figs. 6 and 7 show the temperature and velocity profile for case 1(collector 3) at selected flow velocity of $0.0226 \mathrm{~m} / \mathrm{s}$ while the other ones have similar profiles to the selected flow velocities. The velocity profile showed the air domain features when subjected to the numerical simulation. Fig. 6 show the isometric and the front view of the PTC and it can be seen from the isometric view that the temperature of the HTF increases along the absorber tube from the inlet of the PTC towards its outlet while the front view show a better view of the temperature profile of the $\mathrm{HTF}$ as compared to the other domain that makes up the PTC.

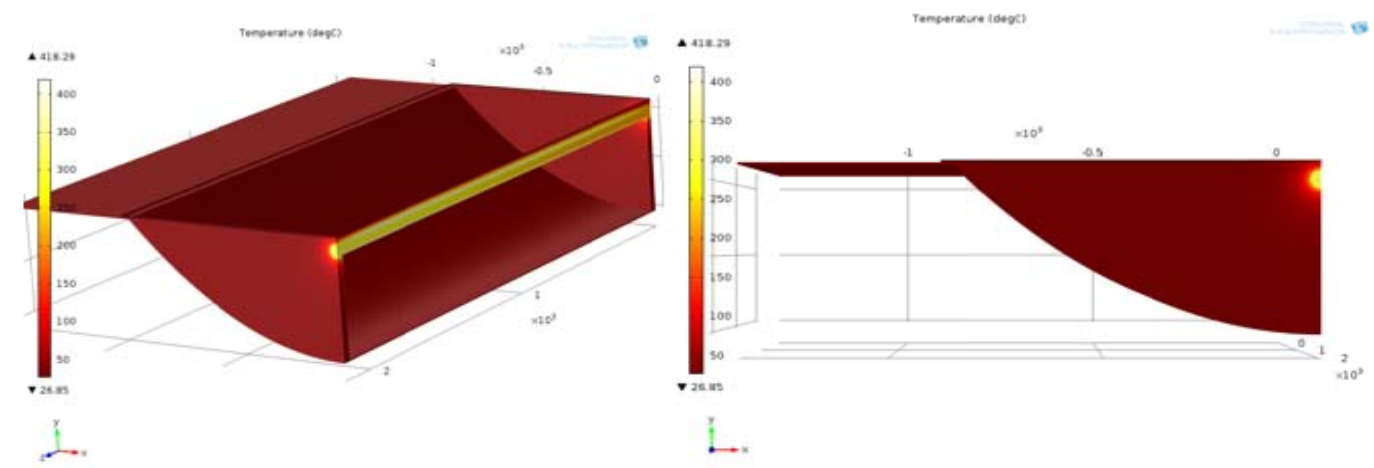

Fig. 6. The temperature profile for Case 1 (collector 3) at $0.0226 \mathrm{~m} / \mathrm{s}$ HTF flow velocity. 


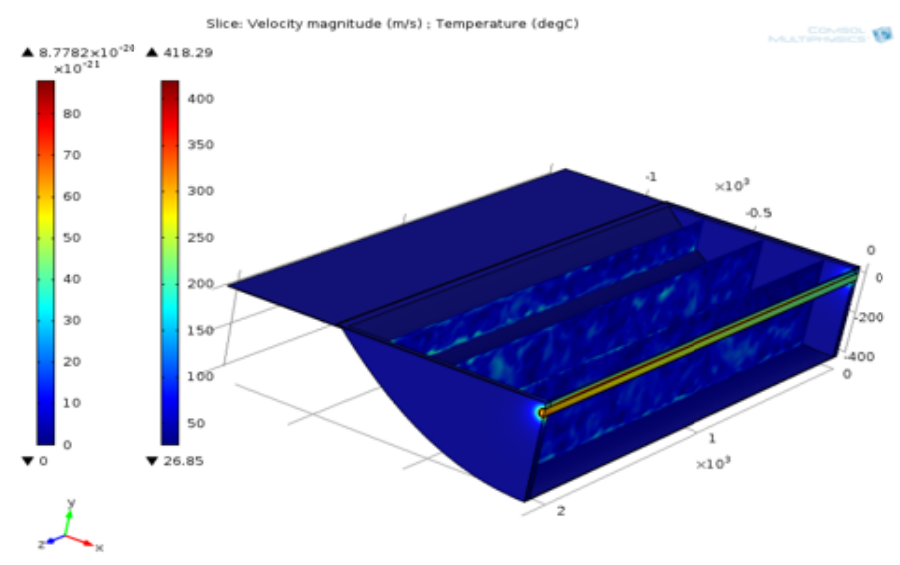

Fig. 7. Combination of velocity magnitude $(\mathrm{m} / \mathrm{s})$ profile and the temperature profile

Fig. 7 show the combination of velocity magnitude $(\mathrm{m} / \mathrm{s})$ profile and the temperature profile. It can be seen that the air surrounding the absorber has a higher temperature and higher velocity magnitude as compared to the other part of the PTC.

Fig. 8 show the temperature profile for case 2 (collector 3 ) when subjected to the same condition as case 1 . It can be seen that the temperature profile is somewhat similar to that of case 1 but the output temperature differs due to the presence of free convection which causes an increases in thermal losses. The velocity magnitude cannot be determined because the air domain has an interaction with the surrounding due to free convection.

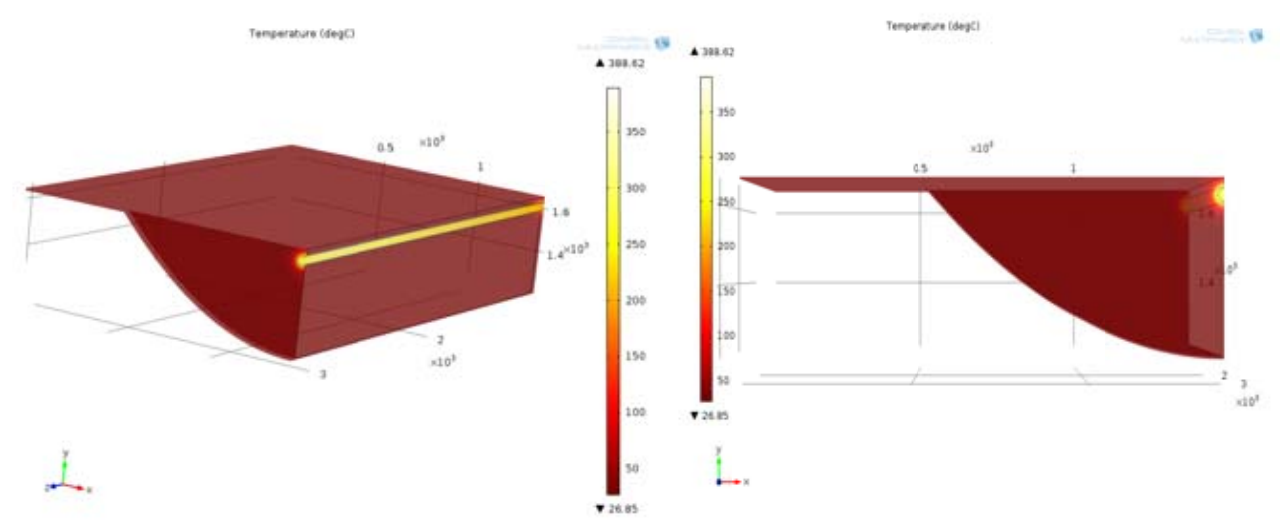

Fig. 8 . The temperature profile for Case 2 (collector 3 ) at $0.0226 \mathrm{~m} / \mathrm{s}$ HTF flow velocity

Using collector 3 as a reference for both cases for the second category, the values of average temperature of the five computational domain under sturdy is given in Tables 8 and 9 below.

TABLE VIII. Case 1: Computational domain average temperature for simulated half-PTC with glass cover at varying velocity

\begin{tabular}{ccccccc}
\hline \hline $\mathbf{S} / \mathbf{N}$ & $\begin{array}{c}\text { Velocity } \\
(\mathbf{m} / \mathbf{s})\end{array}$ & $\begin{array}{c}\mathrm{T}_{\text {abs, }} \text { (average) } \\
\left({ }^{\circ} \mathbf{C}\right)\end{array}$ & $\begin{array}{c}\mathrm{T}_{\text {oil }}(\text { average) } \\
\left({ }^{\circ} \mathbf{C}\right)\end{array}$ & $\begin{array}{c}\mathrm{T}_{\text {air }} \text { (average) } \\
\left({ }^{\circ} \mathbf{C}\right)\end{array}$ & $\begin{array}{c}\mathrm{T}_{\text {glass, }} \text { (average) } \\
\left({ }^{\circ} \mathbf{C}\right)\end{array}$ & $\begin{array}{c}\mathrm{T}_{\text {PVC, }} \text { (average } \\
) \\
\left({ }^{\circ} \mathbf{C}\right)\end{array}$ \\
\hline 1 & 0.0100 & Nil & Nil & Nil & Nil & Nil \\
2 & 0.0226 & 370.98 & 270.17 & 55.10 & 32.54 & 29.09 \\
3 & 0.0452 & 182.08 & 156.44 & 37.97 & 29.01 & 28.00 \\
4 & 0.1100 & 119.07 & 101.88 & 33.20 & 28.05 & 27.47 \\
5 & 0.1350 & 107.9 & 90.04 & 32.36 & 27.90 & 27.38 \\
6 & 0.1580 & 98.92 & 81.21 & 31.72 & 27.76 & 27.32 \\
7 & 0.1810 & 90.77 & 73.87 & 31.14 & 27.65 & 27.26 \\
\hline \hline
\end{tabular}

TABLE IX. Case 2: Computational domain average temperature for simulated half-PTC without glass cover at varying velocity 


\begin{tabular}{ccccccc}
\hline \hline $\mathbf{S} / \mathbf{N}$ & $\begin{array}{c}\text { Velocity } \\
(\mathbf{m} / \mathbf{s})\end{array}$ & $\begin{array}{c}\mathrm{T}_{\text {abs, }}(\text { average } \\
\mathbf{)}\end{array}$ & $\begin{array}{c}\mathrm{T}_{\text {oil }}(\text { average) } \\
\left({ }^{\circ} \mathbf{C}\right)\end{array}$ & $\begin{array}{c}\mathrm{T}_{\text {air }} \text { (average) } \\
\left({ }^{\circ} \mathbf{C}\right)\end{array}$ & $\begin{array}{c}\mathrm{T}_{\text {glass, }} \text { (averag } \\
\mathbf{e}) \\
\left({ }^{\circ} \mathbf{C}\right)\end{array}$ & $\begin{array}{c}\mathrm{T}_{\text {PVC, }} \text { (averag } \\
\mathbf{e}) \\
\left({ }^{\circ} \mathbf{C}\right)\end{array}$ \\
\hline 1 & 0.0100 & Nil & Nil & Nil & Nil & Nil \\
2 & 0.0226 & 346.59 & 255.46 & Nil & Nil & 27.57 \\
3 & 0.0452 & 174.99 & 153.14 & Nil & Nil & 27.26 \\
4 & 0.1100 & 117.17 & 99.95 & Nil & Nil & 27.09 \\
5 & 0.1350 & 106.21 & 88.37 & Nil & Nil & 27.05 \\
6 & 0.1580 & 97.39 & 79.75 & Nil & Nil & 27.03 \\
7 & 0.1810 & 89.11 & 72.34 & Nil & Nil & 27.01 \\
\hline \hline
\end{tabular}
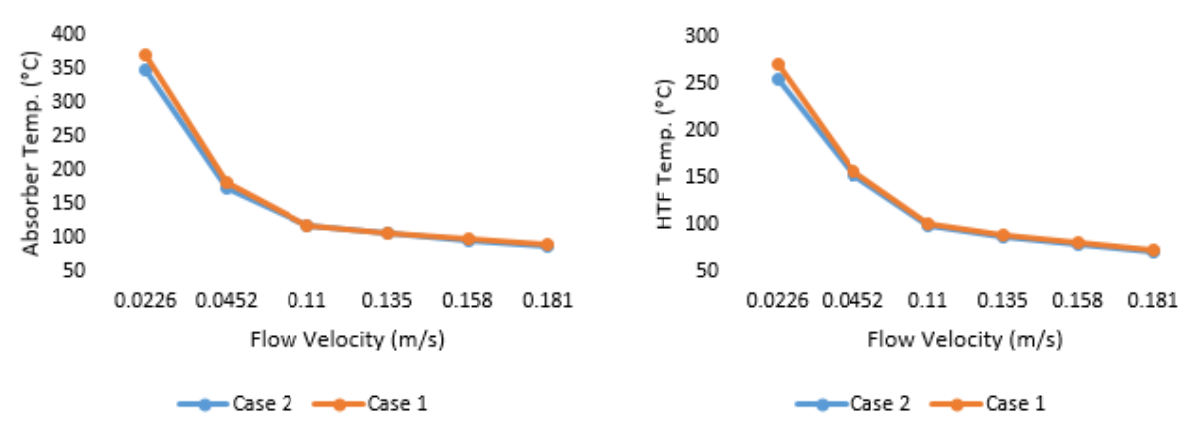

Fig. 9. Average Temperature of absorber tube and HTF for the two cases of collector 3

By comparing the two Tables above (i.e. Table 8 and 9) it show that the computational domain average temperature of case 1 is higher than that of case 2 , which proves further that case 1 has a higher performance than case 2. Fig. 9 show the average temperature of absorber tube and the HTF for the two cases studied and it can be deduced that average temperature of case 1 is greater than that of case 2, therefore influencing the performance of the collectors.

Table 10 show the convective heat loss and the efficiency of the PTC while using collector 3 as a reference for both cases. The heat output $\left(Q_{\text {out }}\right)$ can be given as:

$$
Q_{\text {out }}=\dot{m} C_{p} \Delta T
$$

Where; $\dot{m}$ is the mass flow rate of the HTF and it is a function of the oil density and velocity. While $C_{p}$ is the specific heat capacity of the HTF at constant pressure. It is assumed to be constant at $2.25 \mathrm{~kJ} / \mathrm{kg}^{\circ} \mathrm{K}$ since there is no significant change in its value with large change in temperature.

Also, the efficiency $(\eta)$ can be calculated as

$$
\eta=Q_{\text {out }} / P_{\text {tot }}
$$

\begin{tabular}{|c|c|c|c|c|c|c|c|c|}
\hline $\begin{array}{l}\text { Velocit } \\
\text { y (m/s) }\end{array}$ & $\begin{array}{c}\text { Case } 1: \Delta T \\
\left({ }^{\circ} \mathbf{K}\right)\end{array}$ & $\begin{array}{c}\text { Case 2: } \\
\Delta T \\
\left({ }^{\circ} \mathbf{K}\right)\end{array}$ & $\begin{array}{c}\text { Case } 1 \\
Q_{\text {loss,conv }} \\
\text { (W) }\end{array}$ & $\begin{array}{c}\text { Case 2 } \\
Q_{\text {loss,conv }} \\
\text { (W) } \\
\end{array}$ & $\begin{array}{c}\text { Case } 1 \\
Q_{\text {out }} \\
\text { (W) }\end{array}$ & $\begin{array}{c}\text { Case } 1 \\
Q_{\text {out }} \\
\text { (W) }\end{array}$ & $\begin{array}{c}\text { Case } 1 \\
\eta(\%)\end{array}$ & $\begin{array}{r}\text { Case } 2 \\
\eta(\%)\end{array}$ \\
\hline 0.0100 & Nil & Nil & Nil & Nil & Nil & Nil & Nil & Nil \\
\hline 0.0226 & 96.70 & 90.97 & 0 & 220.69 & 957 & 901 & 54.5 & 51.3 \\
\hline 0.0452 & 55.29 & 52.52 & 0 & 101.69 & 983 & 934 & 56.0 & 53.2 \\
\hline 0.1100 & 29.26 & 28.48 & 0 & 62.10 & 1343 & 1307 & 76.5 & 74.4 \\
\hline 0.1350 & 26.26 & 25.52 & 0 & 54.61 & 1465 & 1424 & 83.4 & 81.1 \\
\hline 0.1580 & 23.66 & 22.91 & 0 & 48.56 & 1507 & 1459 & 85.8 & 83.1 \\
\hline 0.1810 & 21.25 & 20.51 & 0 & 42.88 & 1563 & 1509 & 89.0 & 86.0 \\
\hline
\end{tabular}

TABLE X. The efficiency of the PTC while using collector 3 as a reference for both cases 
It can be deduced from Table 10 that there is no convective heat loss from the absorber tube in case 1 because of the presence of glass cover thereby increasing the performance and efficiency of the PTC unlike case 2 where there is an increase in convective heat loss as the HTF velocity decreases which in turn affected its performance and efficiency. It can also be seen from Table 10 and Fig 10 below that the efficiency of Case 1 is higher than that of Case 2, which proves further that case 1 is a better choice in terms of design, efficiency and performance also as the velocity of HTF increases the efficiency increases which signifies that at higher velocity range there is a better output efficiency.

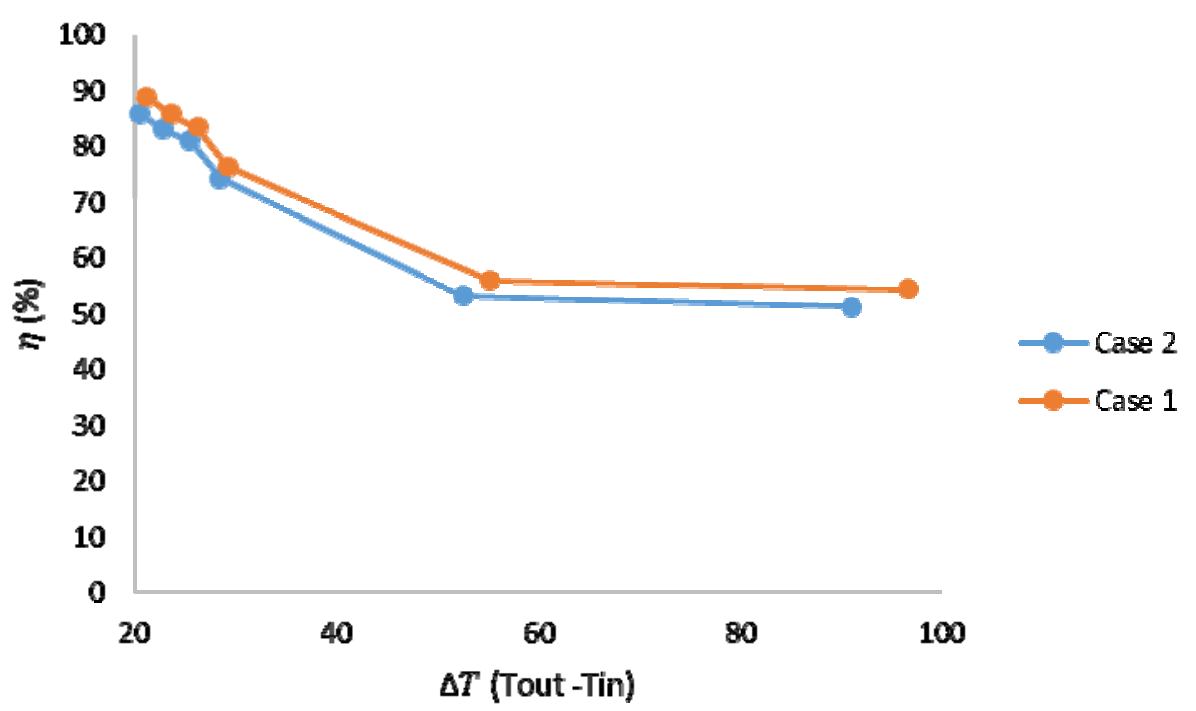

Fig. 10 Plot of efficiency against temperature difference for the two cases.

\section{CONCLUSION}

From the results shown and discussed above it can be concluded that the parabolic trough collector design with flat glass cover in the aperture plane has higher thermal performance and efficiency than the one without flat glass cover in its aperture plane. Therefore with an addition of flat glass cover in the aperture plane, the PTC design will not only have a more rigid and better structure but also an improved maintenance characteristics coupled with a better temperature output.

\section{ACKNOWLEDGMENT}

This project was funded by the National Plan for Science, Technology and Innovation (MAARIFAH) - King Abdulaziz City for Science and Technology - the Kingdom of Saudi Arabia - award number (11-ENE2004-03). The authors also acknowledge with thanks, Science and Technology Unit, King Abdulaziz University for their technical support.

\section{REFERENCES}

[1] Thomas, H.M. Guven; Parabolic trough concentrators - Design, Construction and Evaluation. Energy Convers. Mgmt. vol. 34, No 5, pp. 401-416; 1993

[2] F. Muhammad-Sukki, R. Ramirez-Iniguez, S.G. McMeekin, B.G. Stewart \& B. Clive; Solar Concentrators, International Journal of Applied Sciences (IJAS), Volume (1): Issue (1), 2010

[3] A. Fernandez-Garcia, E. Zarza, L. Valenzuela, M. Perez; Parabolic-trough solar collectors and their applications, Renewable and Sustainable Energy Reviews 2010;pp1696

[4] Soteris Kalogirou; Use of parabolic trough solar energy collectors for sea-water desalination, Applied Energy Journal 1998; pp 66

[5] A. Valan Arasu and T. Sornakumar; Design, manufacture and testing of fiberglass reinforced parabola trough for parabolic trough solar collectors. Solar Energy 81 (2007); pp. 1273-1279

[6] H. Price, R. Forristall et al; Field Survey of Parabolic Trough Receiver Thermal Performance, ASME International Solar Energy Conference; July 8-13, 2006.

[7] E. Luepfert; M. Geyer et al; EuroTrough Parabolic trough Collector Family Developed and qualified for cost efficient solar Power Generation. SolarPaces Zuerich2002

[8] Price H, Luepfert E et al; Advances in parabolic trough solar power technology. J Sol Energy Eng 2002; 124:109-17

[9] Sargent \& Lundy LLC Consulting Group; Executive Summary: Assessment of Parabolic Trough and Power Tower Solar Technology Cost and Performance Forecasts, National Renewable Energy Laboratory; October 2003

[10] Soteris A. Kalogirou; Solar thermal collectors and applications. Progress in Energy and Combustion Science 30; (2004) 231-295

[11] M. M Rolim, N, Fraidenraich, C, Tiba; Analytic modelling of a solar power plant with parabolic linear collectors, Solar Energy 83 (2009) 126-133

[12] D, Chemisana, J, Barrau, J.I. Rosell et al; Optical performance of solar reflective concentrators: A simple method for optical assessment, Renewable Energy 57 (2013) 120129

[13] Dassault Systèmes SolidWorks 2014, release October 7, 2013. 
[14] Faissal Abdel-Hady, Saani Shakil, Mostafa Hamed, Abdulrahim Alzahrani, Abdel-Hamid Mazher; Design, simulation and manufacturing of an integrated composite material parabolic trough solar collector, International Journal of Engineering and Technology (IJET), Vol 8 No 5,2016.

[15] Aranzazu Fernandez-Garcia, Esther Rojas, Manuel Perez, Ricardo Silva, Quetzalcoatl Hernandez-Escobedo, Francisco ManzanoAgugliaro; A parabolic-trough collector for cleaner industrial process heat, Journal of Cleaner production, 2015, pp 272-285

[16] Faghri Amir, Zhang Yuwen, Howell John, Advanced Heat and Mass Transfer, Global Digital Press, Columbia, 2010.

[17] Bejan, A., Convection Heat Transfer, John Wiley \& Sons, 3rd edition. New York, NY. 2004.

[18] COMSOL 4.3; Heat Transfer Module User's Guide, May 2012.

[19] 3M cool mirror film, "http://www.3m.com/solar," accessed on 4th September, 2015.

\section{AUTHOR PROFILE}

Faissal Abdel-Hady joined the Department of Chemical \&Materials Engineering at King Abdulaziz University in 2009. He received his BS and MS degrees from Ain Shams University, Cairo, Egypt in1975and1985, respectively. He received his Ph.D. in Mechanical Engineering from mutual cooperation between Ain Shams University, Egypt and Ecole des Mines de Saint Etienne, France. During the period 1999-2006 he was Senior Research Fellow at Auburn University, Alabama, USA. During that period he worked for NASA in developing energy storage system for the new space shuttle. He was associate professor at Bemidji State University, Minnesota, USA, from 2006 to 2009.

Azeez Bakare is undergoing his Master's degree from Mechanical Engineering Department of King Abdulaziz University. His thesis is based on modelling and performance evaluation of solar concentrators in which the above project work is part of his thesis requirement. He hopes to continue further research on energy sustainability and its cost evaluation and non-destructive evaluation of materials.

Mostafa Hamed is a Professor in the department of Mechanical Engineering. He did his PhD from University of South Carolina, USA in 1981. 